\title{
NILAI TAMBAH PENGOLAHAN BUAH STROBERI MENJADI JUICE DOUBLE BERRY (STUDI KASUS COFFE D'MOOAT DI DESA MOOAT KABUPATEN BOLAANG MONGONDOW TIMUR)
}

\author{
Dormina Mike Sombuk \\ Agnes Estephina Loho \\ Rine Kaunang
}

\begin{tabular}{ll}
\hline Naskah diterima melalui Website Jurnal Ilmiah agrisosioekonomi@ unsrat.ac.id & : Jumat, 12 Juli 2019 \\
Disetujui diterbitkan & : Selasa, 23 Juli 2019 \\
\hline
\end{tabular}

\begin{abstract}
This study aims to analyze the added value of strawberry processing into double berry juice at Caffe D'Mooat in Mooat Village, East Bolaang Mongondow Regency. The research location was chosen deliberately, namely the area that cultivated strawberries in Bolaang Mongondow Timur District, Mooat Village. This research was conducted from August to October 2018. The Caffe D'Mooat research site was in Mooat Village, Bolaang Mongondow Timur Regency. The data used are primary data and secondary data. Primary data is data obtained from observations and direct interviews with the owner of Caffe D'Mooat (one respondent) based on the questionnaire (questionnaire) that had been prepared previously. Secondary data was obtained from Caffe D'Mooat's profile, local bookstore, internet through google scholar to get electronic books, journal articles and thesis related to the topic of research on the added value of strawberry fruit. The method used in this study is a case study method. Data obtained were analyzed using value added according to the method of Hayami et al. (1987). The results of this study indicate that in one process the production of double berry juice provides added value of Rp. $68.54 / \mathrm{gram}{ }^{*}$ eprm*
\end{abstract}

Keywords: Added Value, Double Berry, Caffe D'Mooat, Hayami Method.

\begin{abstract}
ABSTRAK
Penelitian ini bertujuan untuk menganalisis nilai tambah pada pengolahan buah stroberi menjadi juice double berry di Caffe D'Mooat di Desa Mooat Kabupaten Bolaang Mongondow Timur. Lokasi penelitian dipilih secara sengaja yaitu daerah yang membudidayakan stroberi di Kabupaten Bolaang Mongondow Timur Desa Mooat. Penelitian ini dilaksanakan pada bulan Agustus sampai pada bulan Oktober 2018. Tempat penelitian Caffe D'Mooat di Desa Mooat Kabupaten Bolaang Mongondow Timur. Data yang digunakan adalah data primer dan data sekunder. Data primer merupakan data yang diperoleh dari pengamatan dan wawancara langsung dengan pemilik Caffe D'Mooat (satu responden) berdasarkan daftar pertanyaan (kuesioner) yang sudah disusun sebelumnya. Data sekunder diperoleh dari profil Caffe D'Mooat, toko buku lokal, internet melalui google scholars untuk mendapatkan buku elektronik, artikel jurnal dan skripsi yang berkaitan dengan topik penelitian tentang nilai tambah buah stroberi. Metode yang digunakan dalam penelitian ini adalah metode studi kasus. Data yang diperoleh dianalisis menggunakan nilai tambah menurut metode Hayami dkk, (1987). Hasil penelitian ini menunjukan bahwa dalam satu kali proses produksi juice double berry memberikan nilai tambah sebesar Rp. 68.54/gram. ${ }^{* e p r m *}$
\end{abstract}

Kata kunci : Nilai Tambah, Double Berry, Caffe D’Mooat, Metode Hayami. 


\section{PENDAHULUAN}

\section{Latar Belakang}

Tanaman Stroberi (Fragaria $s p$ ) merupakan tanaman buah herba yang ditemukan pertama kali di Chili, Benua Amerika. Stroberi atau strawberry merupakan salah satu komoditas buah-buahan yang penting di dunia, terutama untuk negara-negara beriklim subtropis. Daya serap pasar (konsumen) terhadap stroberi semakin tinggi, hal ini berarti agribisnis stroberi mempunyai prospek cerah (Rukmana, 1998).

Agroindustri adalah salah satu subsitem yang bersama-sama subsistem lain membentuk agribisnis. Sistem agribisnis terdiri dari subsistem input (agroindustri hulu), usahatani (pertanian), sistem output (agroindustri hilir), pemasaran dan penunjang. Dengan demikian pembangunan agroindustri akan dapat meningkatkan produksi, harga hasil pertanian, serta dapat menghasilkan nilai tambah hasil pertanian (Masyuri, 1994 dalam Mokodongan dkk, 2017).

Ciri khas produk pertanian ada mudah rusak dan juga bersifat musiman atau memiliki volume besar tetapi nilainya relatif kecil (bulky) membuat petani harus mampu berpikir bagaimana agar produk pertanian dapat menghasilkan nilai tambah dan keuntungan yang lebih, dengan cara mengolah bahan baku yang ada dengan melalui berbagai proses produksi (Manueke dkk, 2016).

Proses mengubah input menjadi output, yaitu bagaimana mengolah bahan baku menjadi produk sehingga memiliki nilai tambah dan keuntungan. Salah satu produk pertanian yang digunakan sebagai bahan baku industri adalah buah stroberi, yang digunakan untuk membuat jus dauble berry, yang diolah menjadi minuman. Adanya keterkaitan antar sektor pertanian dan industri, dapat peningkatan hasil pertanian (agroindustri). Pengembangan ini dapat meningkatkan nilai tambah produk pertanian dan memperluas penciptaan lapangan kerja.

Stroberi adalah salah satu buah-buahan yang mempunyai nilai ekonomi tinggi karena memiliki bentuk yang mungil, warna sangat menarik, dan cita rasa yang manis dan segar. Buah stroberi dimanfaatkan sebagai makanan dalam keadaan segar atau olahannya. Produk makanan dan minuman yang dibuat dari stroberi telah banyak dikenal seperti sirup, jus stroberi, dodol, es krim, selai, salad buah, dan juga stroberi pada kue dan lain sebagainya atau bisa langsung di konsumsi dalam keadaan segar dan juga bisa langsung dipasarkan ke pasar swalayan, hotelhotel dan restoran bertaraf internasional. Buah Stroberi mempunyai kandungan nutrisi (gizi) yang cukup tinggi terutama kalsium, vitamin $\mathrm{C}$ dan karbonhindrat.

D'Mooat telah membudidayakan stroberi dan mengolah buah stroberi menjadi berbagai produk olahan yang dapat meningkatkan harga pada produk yang diperoleh setelah mengalami proses produksi. Produk yang dihasilkan di caffe D'Mooat adalah juice stroberi, stroberi smoothie, juice naga berry dan juice double berry dari keempat produk olahan tersebut terdapat tiga produk olahan yang telah diteliti oleh Loho dkk (2018), yaitu juice stroberi sebesar Rp. 36,500/gram, stroberi smoothie sebesar Rp. $68,000 /$ gram dan juice naga berry sebesar Rp. $66,500 /$ gram namun ada satu produk yang belum di teliti oleh Loho dkk (2018), yaitu juice double berry hal ini yang mendorong penulis untuk menghitung nilai tambah pada juice double berry dengan nilai tambah sebesar Rp 68.54/gram di Caffe D'Mooat di Desa Mooat Kabupaten Bolaang Mongondow Timur.

\section{Penelitian Terdahulu}

Bunda dkk (2014), dengan judul Nilai Tambah Agroindustri Stroberi (Studi Kasus Pada Agroindustri Kharisma Di Desa Alam Endah Kecamatan Rancabali Kabupaten Bandung). Program Studi Agribisnis. Fakultas Pertanian Universitas Siliwangi. Menunjukan bahwa nilai tambah yang diperoleh dari pengolahan stroberi menjadi dodol stroberi sebesar Rp 24.265,66/kg, selai stroberi sebesar Rp $9.432,14 / \mathrm{kg}$ dan sirup stroberi sebesar $\mathrm{Rp}$ $11.060,71 / \mathrm{kg}$. Keuntungan yang diperoleh pengusaha dari pengolahan stroberi menjadi dodol stroberi sebesar $\mathrm{Rp} 21.640,66 / \mathrm{kg}$, selai stroberi sebesar Rp 7.932,14/kg dan sirup stroberi sebesar Rp 9.810,71/kg.

Loho dkk (2018), dengan judul Evaluasi Agribisnis Stroberi di Bolaang Mongondow Timur menunjukkan bahwa nilai tambah stroberi untuk jus (juice) stroberi sebesar Rp. 36,500/gram, stroberi smoothie sebesar Rp. $68,000 /$ gram, dan naga berry sebesar Rp. $66,500 /$ gram. 
Imani (2016), dengan judul Analisisi Keuntungan Dan Nilai Tambah Pengolahan Ubikayu (Manihot Esculenta) Menjadi Tela-tela (Studi Kasus Usaha Tela Steak Di Kelurahan Mandonga Kecamatan Mandonga Kota Kendari). Menunjukan bahwa usaha pengolahan ubikayu memberikan keuntungan sebesar Rp. 30.828 .000 per dua puluh tiga kali proses produksi selama satu bulan dan menciptakan nilai tambah sebesar Rp. 15.498 per kg bahan baku. Rasio nilai tambah terhadap nilai produk sebesar $72,56 \%$. Artinya untuk setiap Rp 100 nilai produk akan di peroleh nilai tambah $\mathrm{Rp} 72$.

Mokodongan dkk (2017), dengan judul Nilai Tambah Keripik Pisang pada Industri Rumah Tangga Ibu Dewi (Studi Kasus Kecamatan Malalayang). Menunjukkan bahwa besarnya nilai tambah dari usaha pengolahan pisang menjadi keripik pisang adalah Rp. 232.555,48 dan untuk besarnya nilai yang ditambahkan pada bahan baku keripik pisang, maka 232.555.48 dibagi dengan 100 buah pisang hasilnya $2.325,55$, artinya untuk setiap buah pisang yang diolah menjadi kripik pisang dapat memberikan penambahan nilai sebesar 2.325,55.

Mahdalena dan Roliani (2018), dengan judul Analisis Nilai Tambah Usaha Rumah Tangga Asinan Cempedak Di Desa Riwa Kecamatan Batu Mandi Kabupaten Balangan. Nilai tambah berasal dari asinan cempedak adalah Rp.59.660 / $\mathrm{kg}$. Rasio nilai tambah asinan cempedak adalah sebesar $59,07 \%$, artinya setiap satu asinan produksi satu kilogram cempedak menghasilkan nilai $6 \%$.

Manueke dkk (2016), dengan judul Analisis Nilai Tambah Kacang Sangrai Pada UD. Tarsius Di Desa Kinnali Kecamatan Kawangkoan. Menunjukan bahwa Nilai Tambah yang diperoleh Untuk $1 \mathrm{~kg}$ kacang mentah menjadi 0.73 kacang sangrai yaitu sebesar Rp. 4.105,4 dan Nilai Tambah Untuk 0.73 kacang sangrai menjadi kacang sangrai yang sudah dikemas yaitu Rp. 6.169,5.

Simin (2014), dengan judul Analisis Nilai Tambah Buah Pisang Menjadi Keripik Pisang Pada Industri Rumah Tangga Sofie Di Kota Palu. Meningkatkan nilai tambah yang dihasilkan oleh industry Sofie sebesar Rp. 34.533,34/kg. Rasio nilai tambah merupakan persentase antara nilai tambah dengan nilai output. Besarnya rasio nilai tambah pada industri Sofie sebesar $81,44 \%$. Yang berarti hasil dari rasio nilai tambah terhadap nilai produk sebesar 81,44\%, menunjukan bahwa setiap Rp 100 nilai produk keripik pisang akan diperoleh nilai tambah sebesar Rp. 81,44.

\section{Rumusan Masalah}

Berdasarkan latar belakang yang telah diuraikan maka yang menjadi rumusan masalah dalam penelitian ini adalah di caffe D'Mooat ada empat produk yang dihasilkan yaitu juice stroberi, stroberi smoothie, juice naga berry dan juice double berry dari keempat produk olahan tersebut terdapat tiga produk olahan yang telah diteliti oleh Loho dkk (2018) yaitu juice stroberi, stroberi smoothie dan juice naga berry namun ada satu produk yang belum di teliti oleh Loho dkk (2018) yaitu juice double berry hal ini yang mendorong penulis untuk menghitung nilai tambah pada juice double berry di Caffe D’Mooat.

\section{Tujuan Penelitian}

Tujuan penelitian ini bertujuan untuk menganalisis nilai tambah pengolahan buah stroberi menjadi juice double berry di Caffe D'Mooat di Desa Mooat Kabupaten Bolaang Mongondow Timur.

\section{Manfaat Penelitian}

Penelitian ini dapat bermanfaat bagi:

a. Pengusaha/Masyarakat sebagai bahan informasi dan mengetahui pentingnya nilai tambah pada buah stroberi.

b. Penulis

Selain untuk penyelesaian studi akhir, juga dapat menambahkan pemahaman dan pengetahuan bagi penulis dan penelitian selanjutnya.

\section{METODE PENELITIAN}

\section{Waktu dan Tempat Penelitian}

Penelitian ini berlangsung selama 3 bulan mulai dari bulan Agustus sampai pada bulan Oktober 2018. Tempat penelitian di Desa Mooat Kabupaten Bolaang Mongondow Timur.

\section{Metode Pengumpulan Data}

Data yang digunakan dalam penelitian ini adalah data primer Data primer merupakan data yang diperoleh dari pengamatan dan wawancara langsung dengan pemilik Caffe D'Mooat (responden) berdasarkan daftar pertanyaan (kuesioner) yang telah disediakan.

\section{Metode Penelitian}

Metode yang digunakan dalam penelitian ini adalah metode studi kasus. Lokasi penelitian dipilih secara sengaja yaitu daerah yang membudidayakan stroberi di Kabupaten Bolaang Mongondow Timur Desa Mooat. 


\section{Variabel Penelitian}

Seluruh proses produksi jamur tiram putih pada Bella Farm adalah 90 hari atau sekitar tiga bulan lamanya.

1. Output adalah jumlah produk juice double berry yang dihasilkan dalam satu kali proses produksi (Gelas).

2. Input adalah jumlah bahan baku stroberi yang digunakan untuk satu kali produksi (Gram/gelas).

3. Tenaga kerja adalah jumlah yang digunakan dalam pengolahan juice double berry (HOK/menit/gelas).

4. Faktor konversi adalah banyaknya output yang dapat dihasilkan dalam satu satuan input, yaitu banyaknya produk atau jenis produk yang dihasilkan dari satu gram buah stroberi (Output).

5. Koefisien tenaga kerja adalah banyaknya tenaga kerja langsung yang diperlukan untuk mengolah satu gram satuan input (HOK/gram/gelas).

6. Harga output adalah harga jual juice double berry produk persatuan gram (Rp/gelas).

7. Upah tenaga kerja adalah upah rata-rata yang diterima tenaga kerja langsung dengan mengolah produk ( $\mathrm{Rp} / \mathrm{HOK})$.

8. Harga bahan baku adalah harga beli bahan baku buah stroberi (Rp/gram).

9. Sumbangan input adalah biaya pemakaian input dalam bahan baku per gram produk (Rp/gram).

10. Nilai output adalah nilai output jenis produk yang dihasilkan dalam satuan gelas dari satu gram buah stroberi (Rp/gelas) nilai tambah.

\section{Analisis Data}

Analisis data yang digunakan dalam penelitian ini adalah analisis nilai tambah menurut metode Hayami dkk, 1987.

\section{HASIL DAN PEMBAHASAN}

\section{Deskripsi Umum Tempat Penelitian}

Tempat wisata D'Mooat yang sekarang menjadi tempat destinasi wisata yang begitu ramai sudah beroperasi sejak tahun 2017 dan berlokasi di Kawasan Danau Mooat yang terletak di Desa Mooat Kecamatan Mooat Kabupaten Bolaang Mongondow Timur (Boltim). Awalnya tempat wisata D'Mooat hanya menanam tanaman hortikultura. Namun perkembangan sektor parawisata yang semakin ramai memberikan idea Bpk. Eddy Karundeng bersama Ibu. Cyintihia Loho untuk mencoba membuat kebun milik meraka menjadi tempat destinasi wisata dengan menanam stroberi, bunga-bunga dan membuat tempat-tempat untuk pemotretan (foto-foto) juga didirikan caffe yang menyedikan berbagai macam menu makanan dan minuman. Makanan yang mereka sediakan di caffe D'Mooat seperti nasi ayam lalapan, nasi goreng, nasi goreng kampung, mie ayam toge, mie ceplok, mie cekalang, dan ada juga makanan ringan (snack) yaitu pisang goreng, pisang goroho stik, pisang coklat keju, pancake durian, pancake stroberi, salad buah dan menu minuman yang disediakan di caffe D'Mooat adalah juice stroberi, stroberi smoothie, juice naga berry, juice double berry dan lain sebagainya.

Pintu masuk wisata sebelah kanan swa foto-foto dan bunga-bunga sebelah kiri kebun stroberi, tata letak caffe D'Mooat bertempat di tengah-tengah tempat destinasi wisata stroberi D'Mooat di selah timur danau mooat dan tanaman hortikultura, sebelah utara jalan masuk ke tempat wisata D'Mooat dan tempat swa foto, sebelah barat kebun stroberi yang di tanam dengan mnggunakan polybag di taru diatas para-para secara berderetan, sebelah selatan rumah hijau (green hause) yang di dalam ditanam dengan bunga-bunga dan juga tempattempat foto yang dapat diabaikan ke danau Mooat.

\section{Proses Pengolahan Juice Double Berry}

Pemetikan buah stroberi dilakukan pada pagi hari satu kali pemetikan dikebun stroberi bisa mencapai $5 \mathrm{~kg}$ buah stroberi per hari. Dalam satu minggu dua kali pemetikan buah stroberi. Proses pengolahan juice double berry dilakukan mulai dari steril, pencucian dan pembuatan juice.

Proses pengolahan tersebut dilakukan oleh 1 orang karyawan dan membutuhkan waktu 7 menit dalam satu kali proses pengolahan. Dalam satu kali proses pengolahan membutuhkan 50 gram bahan baku dengan perbandingan 1:1 untuk membuat juice double berry atau membutuhkan 25 gram stroberi dan 25 gram black berry. Dalam satu hari juice double berry bisa terjual 5 sampai 10 gelas dan harga jual per satu gelas seharga Rp. 22.000. 


\section{Proses Pengolahan Juice Double Berry}

Pengolahan juice double berry di mulai dari penyiapan blender kemudian masukkan bahan baku buah stroberi dilanjutkan dengan masukkan bahan penolong berupa black berry, sirup marjan stroberi, susu putih, gula pasir, es batu, dan air kemudian yang terakhir blender semua bahan untuk mendapatkan hasil akhir juice double berry. Proses pengolahan juice double berry dapat dilihat pada gambar 1 .

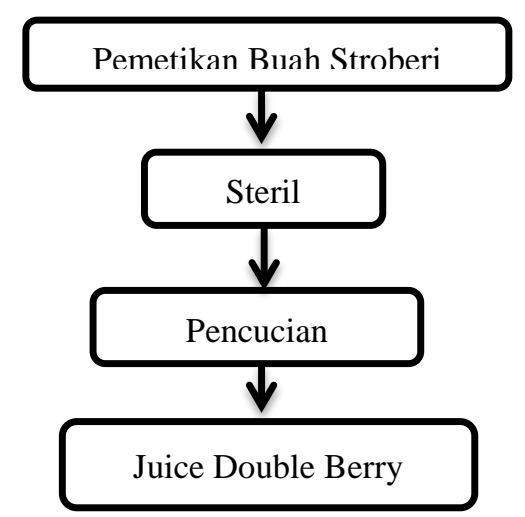

Gambar 1. Proses Pengolahan Juice Double

\section{Penggunaan Peralatan}

Pengadaan peralatan yang tepat dapat membantu melancarkan proses kegiatan pengolahan serta memberikan keuntungan bagi Caffe D'Mooat. Biaya penggunaan peralatan pada Caffe D'Mooat selama proses pengolahan, dapat dilihat pada Tabel 1.

Tabel 1. Biaya Penggunaan Peralatan Untuk Satu Kali Proses Pengolahan Juice Double Berry di Caffe D'Mooat

\begin{tabular}{llccr}
\multicolumn{5}{c}{ D’Mooat } \\
\hline No. & Nama & $\begin{array}{c}\text { Jumlah } \\
\text { Plat }\end{array}$ & $\begin{array}{c}\text { Harga Beli } \\
\text { (Rp/Satuan) }\end{array}$ & Penyusutan \\
\hline 1. & Blender & 1 & 275.000 & 188,36 \\
2. & Loyan & 1 & 20.000 & 41,10 \\
3. & Baki & 1 & 30.000 & 27,40 \\
4. & Gelas Kaki & 1 & 15.000 & 41,10 \\
\hline \multicolumn{5}{l}{ Jumlah } \\
\hline
\end{tabular}

Tabel 1 memperlihatkan biaya penggunaan peralatan yang dikeluarkan oleh usaha pengolahan juice double berry Caffe D’Mooat di Desa Mooat.

\section{Penyediaan Bahan Baku dan Bahan Penolong}

Bahan baku utama yang digunakan dalam proses pengolahan juice double berry adalah buah stroberi yang dipetik dari kebun sendiri. Bahan baku adalah bahan mentah yang diolah untuk menghasilkan produk pertanian dengan nilai yang lebih tinggi. Ketersediaan bahan baku selalu tersedia sehingga dapat membantu keberlanjutan proses pengolahan di caffe D'Mooat. Selain bahan baku ada juga bahan penunjang atau bahan penolong yang dipakai untuk proses pengolahan juice double berry di caffe D'Mooat, bahan penolong yang dipakai adalah black berry, sirup marjan stroberi, susu putih, gula pasir, es batu dan air. rincian penggunaan biaya bahan baku dan bahan penolong dapat dilihat pada Tabel 2 .

\begin{tabular}{|c|c|c|c|c|}
\hline No & Nama Bahan & $\begin{array}{c}\text { Jumlah } \\
\text { Pemakaian }\end{array}$ & Satuan $(\mathrm{Kg})$ & $\begin{array}{c}\text { Harga Beli } \\
\text { (Rp/Satuan) }\end{array}$ \\
\hline A & $\begin{array}{l}\text { Bahan Baku } \\
\text { Utama }\end{array}$ & & & \\
\hline 1 & Buah Stroberi & 25 gram & $1 \mathrm{~kg} / 50$ gram & 150.000 \\
\hline \multicolumn{2}{|c|}{ Jumlah } & & & 150.000 \\
\hline B & Bahan Penolong & & & \\
\hline 1 & Black berry & 25 gram & $1 \mathrm{~kg} / 50 \mathrm{gram}$ & 150.000 \\
\hline 2 & $\begin{array}{l}\text { Sirup marjan } \\
\text { stroberi }\end{array}$ & $\begin{array}{l}4 \text { sendok } \\
\text { makan }\end{array}$ & $1 \mathrm{botol} / 450 \mathrm{ml}$ & 20.000 \\
\hline 3 & Susu putih & $\begin{array}{l}1 \text { sendok } \\
\text { makan }\end{array}$ & $\begin{array}{l}1 \text { kaleng/370 } \\
\mathrm{ml}\end{array}$ & 8.100 \\
\hline 4 & Gula pasir & 1 sendok the & $1 \mathrm{~kg}$ & 10.500 \\
\hline 5 & Es batu & $1 / 2$ gelas & $\begin{array}{l}1 \text { batang } \\
\text { plastik }\end{array}$ & - \\
\hline 6 & Air & 2 gelas & 1 gelon & - \\
\hline & Jumlah & & & 338.600 \\
\hline
\end{tabular}

Tabel 2 menunjukkan rincian penggunaan biaya bahan baku dan bahan penolong yang diperlukan dalam proses pengolahan juice double berry di caffe D'Mooat, dimana biaya bahan penolong yaitu black berry menjadi biaya terbesar dalam proses pengolahan dengan jumlah 20.000 dan untuk biaya terendah yaitu susu putih sebesar Rp. 8.100 Jumlah keseluruhan bahan baku dan bahan penolong adalah sebesar Rp. 338.600. Total biaya yang dikeluarkan dari proses pengolahan dapat dilihat pada Tabel 3.

Tabel 3. Penggunaan Bahan Penolong Untuk Pengolahan Juice Double
Berry di Caffe D'Mooat

Tabel 3 memperlihatkan biaya-biaya yang dipakai dalam pengolahan juice double berry di caffe D'Mooat, jumlah total biaya dari biaya bahan penolong dan penyusutan alat sebesar Rp.661.46, yang digunakan untuk pengolahan pengolahan juice double berry di caffe D'Mooat. 


\section{Penerimaan}

Penerimaan adalah jumlah produksi dikalikan dengan harga jual. Penerimaan merupakan semua biaya dari jumlah produksi dalam satu kali proses produksi suatu produk dikalikan dengan harga jual dari produksi atau harga jual per satu gelas juice double berry di caffe D'Mooat.

Penerimaan $=$ Jumlah produk yang dihasilkan $\mathrm{x}$ Harga jual per satu gelas

$$
=8 \times 22.000
$$$$
=176.000
$$

Maka besar penerimaan juice double berry di caffe D'Mooat sebesar Rp.176.000, yang diperoleh dari penerimaan sama dengan jumlah produk yang dihasilkan per hari yaitu 5 sampai 10 gelas, namun di ambil rata-rata yaitu 8 gelas, dikali dengan harga jual per satu gelas dengan harga sebesar Rp. 22.000, jadi total penerimaan dalam satu hari sebesar $\mathrm{Rp}$. 176.000 per hari.

\section{Keuntungan}

Keuntungan juice double berry di caffe D'Mooat dapat dilihat dengan menghitung nilai tambah dikurangi imbalan tenaga kerja.

$$
\begin{aligned}
\text { Keuntungan }= & \text { Nilai Tambah }- \text { Imbalan Tenaga } \\
& \text { Kerja } \\
= & 68.54-4.375 \\
= & 64,165
\end{aligned}
$$

Maka keuntungan yang diperoleh dari pengolahan juice double berry di caffe D'Mooat adalah sebesar Rp. 64,165.

\section{Imbalan Tenaga Kerja}

Imbalan tenaga kerja adalah diperoleh dari perkalian antara koefisien tenaga kerja dengan upah rata-rata tenaga kerja.

Imbalan Tenaga Kerja = Koefisien Tenaga Kerja

$$
\begin{aligned}
& x \text { Upah Rata-Rata } \\
= & 0,28 \times 15,625 \\
= & 4,375
\end{aligned}
$$

Maka besar imbalan tenaga kerja sebesar yang terima untuk pengolahan juice double berry di caffe D’Mooat adalah sebesar Rp 4,375.

\section{Uraian Perhitungan Nilai Tambah}

Nilai tambah adalah selisih antara komoditas yang mendapat perlakuan pada pada tahap tertentu dengan korbanan yang digunakan selama proses produksi berlangsung. Analisis nilai tambah merupakan metode pemikiran bahan baku yang dapat perlakuan khusus untuk mendapatkan nilai tambah. Perhitungan nilai tambah menggunakan metode hayami dengan rumus sebagai berikut : $\mathrm{K}=\mathrm{J}-\mathrm{H}-\mathrm{I}$

Nilai Tambah $=$ Nilai Produk output - Harga Bahan Baku - Sumbangan Input Lain

$$
\begin{aligned}
& =880-150-661.46 \\
& =68.54
\end{aligned}
$$

Maka nilai tambah yang diperoleh dari pengolahan juice double berry di caffe D'Mooat sebesar Rp. 68.54/gram dapat dilihat pada Tabel 4.

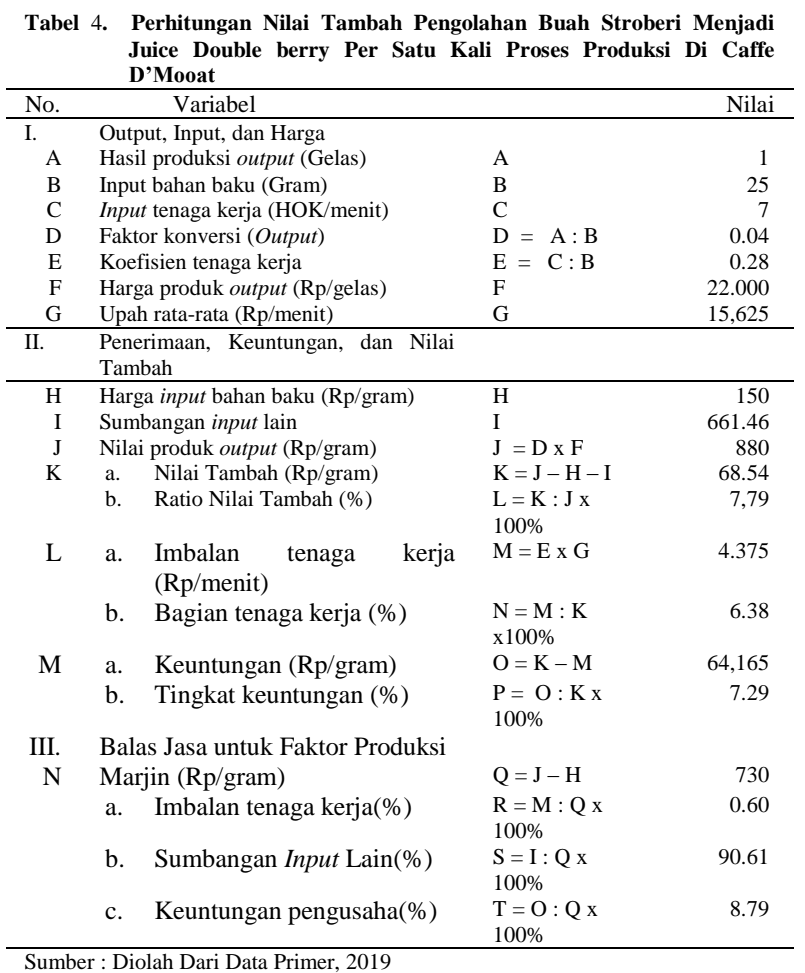

Tabel 4 Hasil produksi (output) adalah satu gelas juice double berry karena setiap ada permintaan dari para konsumen baru dapat diolah. Input adalah jumlah bahan baku yang digunakan untuk satu kali pengolahan juice double berry yaitu membutuhkan 25 gram buah stroberi untuk satu gelas juice double berry.

Tenaga kerja adalah hasil bagi antara tenaga kerja dengan jumlah bahan baku yang digunakan dalam satu kali proses produksi juice double berry menggunakan 1 orang karyawan tenaga kerja dengan waktu yang digunakan sebanyak 7 menit mulai dari steril, pencucuian dan proses pembuatan juice dengan upah rata-rata tenaga kerja sebesar Rp. $15,625 /$ menit. 
Faktor konversi adalah banyaknya output yang dapat dihasilkan dalam satu satuan input, yaitu banyaknya produk atau jenis produk yang dihasilkan dari satu gram buah stroberi (output). Faktor konversi dapat dihitung berdasarkan pembagian antara nilai output yang dihasilkan dengan bahan baku yang digunakan (input). Faktor konversi pada caffe D'Mooat yaitu sebesar 0,04 didapat dari pembagian antara output yang dihasilkan dalam satu kali proses produksi yaitu satu gelas juice double berry dengan input yang digunakan sebesar 25 gram buah stroberi.

Koefisien tenaga kerja adalah banyaknya tenaga kerja langsung yang diperlukan untuk mengolah satu gram satuan input. Koefisien tenaga kerja adalah nilai pembagian dari jumlah jam kerja tenaga kerja yang digunakan dengan jumlah bahan baku yang digunakan dalam proses produksi. Koefisien tenaga kerja menunjukkan banyaknya jam kerja, atau tenaga kerja yang diperlukan untuk mengolah satu-satuan input. Koefisien tenaga kerja pada caffe D'Mooat diperoleh dari pembagian antara waktu tenaga kerja 7 menit dengan bahan baku (input) yang digunakan sebanyak 25 gram, jadi koefisien tenaga kerja yang didapatkan sebesar 0,28. Jadi Koefisien tenaga kerja menunjukkan bahwa satu gram stroberi membutuhkan waktu pengolahan 0,28 menit.

Harga produk (output) adalah harga jual juice double berry sebesar Rp. 22.000/gelas. Upah tenaga kerja adalah upah rata-rata yang diterima tenaga kerja langsung dalam proses pengolahan juice double berry sebesar Rp. 15,625/menit. Harga bahan baku adalah harga beli buah stroberi per gram sebesar Rp. 150.000 namun yang dapat digunakan untuk pengolahan juice double berry sebesar Rp. 150/gram.

Sumbangan input lain atau bahan penolong yang digunakan dalam satu kali proses pengolahan juice double berry dapat dilihat pada Tabel 4, yang menjelaskan penggunaan bahan penolong untuk pengolahan juice double berry di caffe D'Mooat dengan jumlah pemakain sebesar Rp. 661.46.

Nilai output adalah nilai output jenis produk yang dihasilkan dalam satuan gelas dari satu gram buah stroberi. Nilai output merupakan perkalian antara faktor konversi dengan harga produk yang dihasilkan (output). Faktor konversi sebesar 0,04 dikalikan dengan harga jual juice double berry sebesar Rp. 22.000/gelas, sehingga besar nilai produk output yang dihasilkan dari tiap gram buah sebesar Rp. 880/gram.
Nilai tambah adalah selisih nilai output jenis produk dengan nilai bahan baku utama buah stroberi dan sumbangan input lain. Nilai produk output sebesar Rp. 880/gram, dikurangi dengan harga input bahan baku sebesar Rp. 150/gram atau bisa dapat dilihat pada tabel 4 dan sumbangan input lain sebesar Rp. 661.46. Nilai tambah yang dihasilkan dari satu gelas juice double berry di caffe D’Mooat sebesar Rp. 68.54/gram.

Rasio nilai tambah adalah presentase tenaga kerja dari nilai tambah. Rasio nilai tambah merupakan persentase antara nilai tambah dengan nilai output. Besarnya rasio nilai tambah pada pengolahan juice double berry di caffe D'Mooat sebesar $7,79 \%$, tergolong rendah.

Imbalan tenaga kerja adalah hasil kali antara koefisien tenaga kerja dan upah rata- rata tenaga kerja. koefisien tenaga kerja 0,28 dikalikan dengan upah rata- rata tenaga kerja sebesar Rp. $15,625 /$ menit. Maka besarnya imbalan tenaga kerja yang diterima pada pengolahan juice double berry di caffe D'Mooat sebesar Rp. 4.375.

Bagian tenaga kerja diperoleh dari persentase antara imbalan tenaga kerja terhadap nilai tambah. Imbalan tenaga kerja sebesar Rp. 4.375 dibagi dengan nilai tambah sebesar Rp. 68.54/gram dikalikam dengan 100\%, maka bagian tenaga kerja pada pengolahan juice double berry di caffe D'Mooat sebesar 6,38\%.

Keuntungan adalah nilai tambah dikurangi imbalan tenaga kerja. Nilai tambah sebesar Rp. 68.54/gram dikurangi dengan Imbalan tenaga kerja sebesar Rp. 4.375. Maka keuntungan yang dapat diperoleh dari pengolahan juice double berry di caffe D'Mooat sebesar Rp. 64.165.

Tingkat keuntungan adalah presentase keuntungan terhadap nilai tambah. Tingkat keuntungan merupakan selisih antara nilai tambah dengan tenaga kerja, sehingga dianggap sebagai nilai tambah bersih yang diterima oleh perusahaan. Keuntungan yang didapat dari pengolahan juice double berry di caffe D'Mooat sebesar Rp. 64.165, dengan tingkat keuntungan sebesar 7.29\%.

Marjin adalah selisih antara nilai output dengan bahan baku atau besarnya kontribusi pemilik faktor-faktor produksi selain bahan baku yang digunakan dalam proses produksi. Perhitungan balas jasa untuk faktor produksi (marjin) diperoleh dari sumbangan input lain sebesar Rp. 661.46 dikurangi dengan harga input bahan baku sebesar Rp. 150/gram. Maka perhitungan balas jasa untuk faktor produksi (marjin) dari pengolahan juice double berry di caffe D’Mooat sebesar Rp. 730/gram.

Agrisosioekonomi: 
Pendapatan tenaga kerja adalah presentase pendapatan tenaga kerja terhadap marjin. Imbalan tenaga kerja sebesar 4.375/menit dibagi dengan marjin sebesar Rp. 730/gram dan dikalikan dengan $100 \%$, maka imbalan tenaga kerja sebesar $0,60 \%$.

Sumbangan input lain adalah presentase sumbangan input lain terhadap marjin. Sumbangan input lain sebesar Rp. 661.46 dibagi dengan marjin sebesar Rp. 730/gram dan dikalikan dengan $100 \%$, maka sumbangan input lain sebesar 90,61\%.

Keuntungan Pengusaha adalah presentase keuntungan terhadap marjin. Keuntungan sebesar 64,165 dibagi dengan marjin sebesar Rp. 730/gram dan dikalikan dengan 100\%, maka keuntungan pengusaha sebesar $8,79 \%$.

\section{KESIMPULAN DAN SARAN}

\section{Kesimpulan}

Hasil penelitian ini menunjukan bahwa dalam satu kali proses produksi juice double berry memberikan nilai tambah sebesar Rp. 68.54/gram.

\section{Saran}

1. Untuk memperoleh nilai tambah pengusaha terus melakukan efisiensi terutama dalam hal biaya dan penggunaan bahan baku dalam kegiatan pengolahan bahan baku agar lebih dapat meningkatkan nilai tambah pada produkproduk yang dihasilkan.

2. Untuk pengusaha kiranya ada kerja sama antara pemerintah daerah dan masyarakat Desa Mooat Kabupaten Bolaang Mongondow Timur.

\section{DAFTAR PUSTAKA}

Bunda, C. A. P. Unang dan B. Rofatin. 2014. Nilai Tambah Agroindustri Stroberi (Studi Kasus Pada Agroindustri Kharisma Di Desa Alam Endah Kecamatan Rancabali Kabupaten Bandung). Program Studi Agribisnis. Fakultas Pertanian Universitas Siliwangi.
Hayami Y, Kawageo T, Siregar M. 1987. Pemasaran Pertanian dan Pengolahan Di Upland Java; Perspektif dari sebuah Sunda Vilage. CGPRT. Bogor.

Imani, I. 2016. Analisis Keuntungan dan Nilai Tambah Pengolahan Ubikayu (Manihot Esculenta) Menjadi Tela-Tela (Studi Kasus Usaha Tela Steak di Kecamatan Mandonga Kota Kendari). Skripsi Fakultas Pertanian Universitas Halu Oleo Kendari.

Loho A. E., J. Tatuh, G.H.M Kapantow. 2018. Evaluasi Agribisnis Stroberi di Bolaang Mongondow Timur. Jurnal Agrisosieekonomi. Volume 14 Nomor 3, September 2018 : 169176. Fakultas Pertanian Unsrat. ISSN: 19074298.

Mahdalena, M., dan Roliani, S. (2018). Analisis Nilai Tambah Usaha Rumah Tangga Asinan Cempedak Di Desa Riwa Kecamatan Batu Mandi Kabupaten Balangan. Volume 43 Nomor 1, 40-50. Ziaa'ah Majalah Ilmiah Pertanian.

Manueke, R. Mandei, J. R dan P. A Pangemanan, 2016. Analisis Nilai Tambah Kacang Sangrai pada Ud. Tarsius di Desa Kinnali Kecamatan Kawangkoan. Volume 12 Nomor 2A, Juli 2016: 341-348. Fakultas Pertanian Unsrat. Ejournal.unsrat.ac.id.

Mokodongan, W. J . R Mandei, dan J. N Dumais. 2017. Nilai Tambah Keripik Pisang Pada Industri Rumah Tangga Ibu Dewi (Studi Kasus Kecamatan Malalayang). Volume 13 Nomor 3A, November 2017: 27-32. Fakultas Pertanian Unsrat. Ejournal.unsrat.ac.id.

Rukmana, H. R. 1998. Stroberi, Budi Daya dan Pasca Panen. (Cetakan Pertama). Badan Penerbit Kanisius. Yogyakarta. ISBN: 979672-251-8.

Zulkifli. 2012. Analisis Pendapatan Dan Nilai Tambah Pada Agroindustri Kripik Ubi Di Kecamatan Tanah Luas Kabupaten Aceh Utara. Skripsi, Agribisnis, Fakultas Pertanian. Universitas Malikussa. 